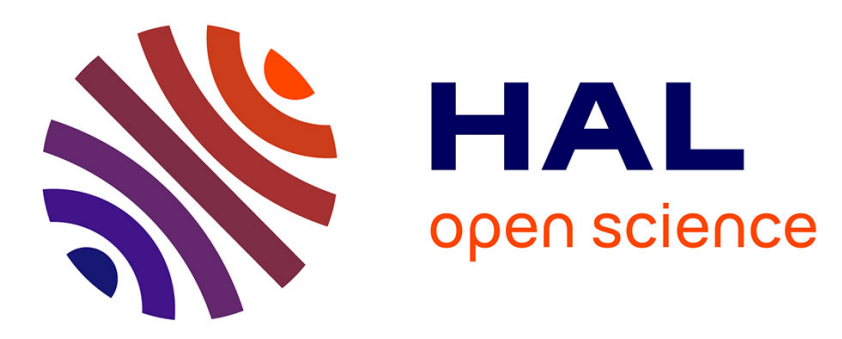

\title{
ABC method for Hysteresis Model Parameters Identification
}

Dounia Sedira, Yasmine Gabi, Afef Kedous-Lebouc, K. Jacob, Bernd Wolter, B. Strass

\section{- To cite this version:}

Dounia Sedira, Yasmine Gabi, Afef Kedous-Lebouc, K. Jacob, Bernd Wolter, et al.. ABC method for Hysteresis Model Parameters Identification. Journal of Magnetism and Magnetic Materials, 2020, $505,10.1016 / \mathrm{j} . j m m m .2020 .166724$. hal-02525847

\section{HAL Id: hal-02525847 \\ https://hal.science/hal-02525847}

Submitted on 27 Nov 2020

HAL is a multi-disciplinary open access archive for the deposit and dissemination of scientific research documents, whether they are published or not. The documents may come from teaching and research institutions in France or abroad, or from public or private research centers.
L'archive ouverte pluridisciplinaire HAL, est destinée au dépôt et à la diffusion de documents scientifiques de niveau recherche, publiés ou non, émanant des établissements d'enseignement et de recherche français ou étrangers, des laboratoires publics ou privés. 


\title{
ABC method for Hysteresis Model Parameters Identification
}

\author{
D. Sedira ${ }^{1}$, Y. Gabi ${ }^{2}$, A. Kedous-Lebouc ${ }^{3}$, K. Jacob ${ }^{2}$, B. Wolter ${ }^{2}$ and B.Straß ${ }^{2}$ \\ ${ }^{1}$ Laboratoire d'électrotechnique et d'électronique industrielle L2EI, \\ Université Mohamed Seddik Ben Yahia, BP98, Jijel 18000, Algeria \\ ${ }^{2}$ Fraunhofer Institute for Nondestructive Testing IZFP, Campus E3, 66123 Saarebruecken, Germany \\ ${ }^{3}$ Univ. Grenoble Alpes, CNRS, Grenoble INP, G2Elab, 21 avenue des Martyrs CS 90624, Grenoble \\ 38031, France
}

\begin{abstract}
The paper deals with the application of the artificial bee colony $(\mathrm{ABC})$ method for hysteresis parameters identification. For the first time, the ABC method will be applied on hysteresis model optimization. For this purpose, two hysteresis models are tested: the first is based on a physical magnetic material behavior, which is Jiles-Atherton and the second is simpler, Fröhlich hysteresis model built on mathematical considerations. This method's robustness will be assessed, by comparing the experimental signals to model results.
\end{abstract}

\section{INTRODUCTION}

Electrical engines and electromagnetic machines are designed according to the customer requests and safety norms. Furthermore, the advanced technologies have to target the optimized operating conditions. For this purpose, it is necessary to build robust numerical modeling based on the magnetic material behavior. In literature, several models have been proposed and studied in large material application. It can be splitted into families: analytical ones: such as Rayleigh [1], Potter [2] or Fröhlich [3][4][5], which offer comfortable implementation in finite element code, but still limited to low or high magnetization behavior description. The second family is based on physical considerations such as the Preisach model [6] and the Jiles-Atherton model [7]. These are considered as the most robust and reliable models can be applied on soft and hard magnetic materials by parameter identification process. This task remains complex due to the inter dependency of each parameter to the other. The first investigation realized in this topic is based on iterative procedure [8]. It leads to good approximation of parameter's values but often presents convergence problems and can engender numerical instability. Other authors have proposed deterministic optimization methods [9][10], where the results were successful but request a great time calculation. Since two decades, stochastic optimization methods like generic algorithms and neural network [11][12][13] have been investigated. Other works combined between generic algorithms and simulated annealing [14]. It results accurate solution in a very short time.

Recently, swarm intelligence method is used in electromagnetic applications. The most famous one is the particle swarm optimization (PSO) [15], inspired by the collective behavior of birds and fishes. Many experts have investigated this method 
in Jiles -Atherton parameters and have assessed the ability of this technique to solve optimization problems [16][17]. In the same class a new method, so called "artificial bee colony method (ABC)", is introduced by D.Karaboga [18], based on the foraging behavior of honey bees. The algorithm offers a global optimization in constrained and unconstrained optimization problems. This algorithm proved its performance compared to other algorithms like GA and PSO [19][20].

During the last decade several studies focused on improving the convergence speed [21][22][23] and it is also used to solve the dynamic optimization problems in[24].

For the first time, this method will be tested and applied for hysteresis model identification. This paper deals with the application of $\mathrm{ABC}$ method to estimate the parameter set of the Jiles-Atherton model. The validation of the proposed procedure is firstly verified in the simple case of Fröhlich model, where the parameters can be derived analytically and then the optimization algorithm will be tested in the most complex case of Jiles-Atherton model. The calculated curves will be compared to the measured ones.

\section{II.JILES-ATHERTON MODEL}

In the original Jiles-Atherton model [7], the magnetization $M$ is decomposed into its reversible components $M_{\text {rev }}$ and its irreversible components $M_{i r r}$ as follows:

$$
M=M_{i r r}+M_{r e v}
$$

The relationship between these two components $M_{\text {rev }}, M_{\text {irr }}$ and the anhysteretic magnetization is obtained from physical considerations of the magnetization process and are given by:

$$
\begin{gathered}
M_{r e v}=c\left(M_{a n}-M_{i r r}\right) \\
\frac{d M_{i r r}}{d H}=\frac{M_{a n}-M_{i r r}}{k \delta-\alpha\left(M_{a n}-M_{i r r}\right)}
\end{gathered}
$$

The anhysteretic magnetization $M_{a n}$ in (2) and (3) follows the Langevin function, which is a nonlinear function of the effective field, $H_{e}=H+\alpha M$ :

$$
M_{a n}=M_{s}\left(\operatorname{coth}\left(\frac{H_{e}}{a}\right)-\frac{a}{H_{e}}\right)
$$


With $\alpha$ is a factor that takes account for interdomain coupling; $c$ is the proportionality constant that accounts for reversible motion; $k$ is a coefficient accounting for the pinning energy; $\delta$ is a directional parameter it takes the value +1 for $d H / d t>0$ and -1 for $d H / d t<0 ; M_{s}$ is the saturation magnetization; $a$ is a normalization constant of the $H$ field.

Combining the irreversible and the reversible components of magnetization, the differential equation for the rate of change of the total magnetization is given by:

$$
\frac{d M}{d H}=(1-c) \frac{M_{a n}-M_{i r r}}{k \delta-\alpha\left(M_{a n}-M_{i r r}\right)}+c \frac{d M_{a n}}{d H}
$$

\section{FRÖHLICH HYSTERESIS MODEL}

The Fröhlich model gives an approximation of the relation between the magnetic induction $B$ and the excitation field $H$. The following relations allow the representation of the hysteresis curve.

For initial magnetization

$$
B(H)=\frac{H}{(\alpha+\beta|H|)}
$$

For upward curve

$$
B(H)=\frac{H-H_{c}}{\left(\alpha+\beta\left|H-H_{c}\right|\right)}
$$

For downward curve

$$
B(H)=\frac{H+H_{c}}{\left(\alpha+\beta\left|H+H_{c}\right|\right)}
$$

Where $\alpha$ and $\beta$ are defined from the characteristic points of an experimental hysteresis curve given in Fig. I:

$$
\alpha=H_{c}\left(\frac{1}{B_{r}}-\frac{1}{B_{s}}\right)
$$




$$
\beta=\frac{1}{B_{S}}
$$

Where $H_{c}$ is the coercitive magnetic field, $H_{s}$ the saturation magnetic field, $B_{r}$ the remanent flux density and $B_{s}$ the saturation flux density.

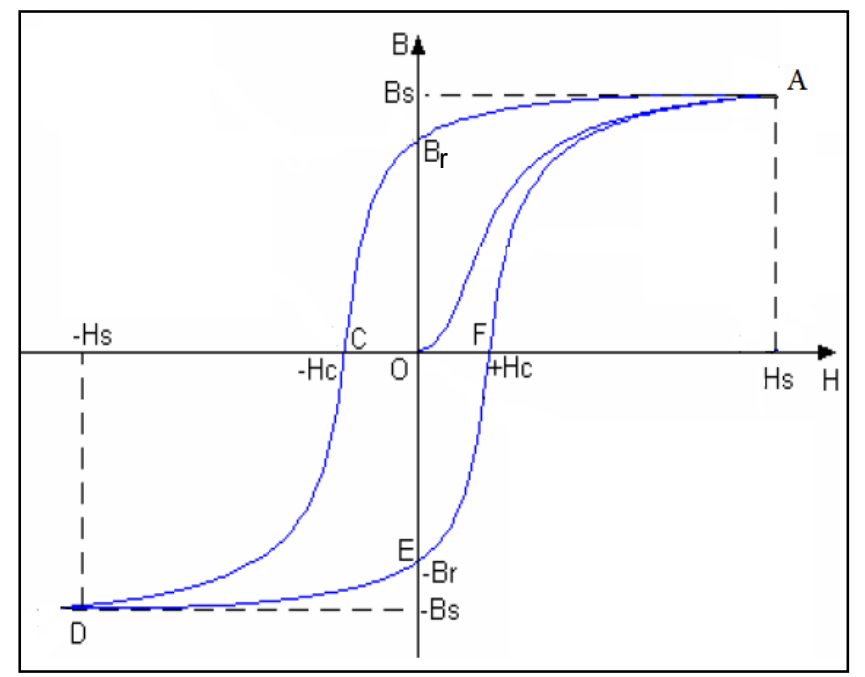

Fig. 1. Characteristic points of hysteresis loop

\section{ARTIFICIAL BEE COLONY ALGORITHM}

\section{A. Principles}

The first study of the ABC method is from Karaboga [18] in optimization of mathematical problems. The machine-learning algorithm is based on the bees' behavior during the nectar collection. The bees are divided in three groups: employed bees, onlookers and the scouts.

The first group, called the "employed bees" is associated to food sources they are exploiting. They carry information like the distance from the hive to their food source and the profitability of it. Coming back to the hive, they indicate the qualitative and quantitative food sources position, by accomplishing a specific dance. The onlooker bees collect the given information and choose the most interesting sources for the exploitation. If a source is exhausted, the employed bee assigned to it becomes a scout looking for other sources. The number of the employed bees is the same as the number of food sources and is about half the swarm size.

\section{B. Algorithm}

In the optimization algorithm, the potential optima represent the food sources and the quality of the nectar is the fitness cost. The onlooker bees chose food sources according to a selection probability. If an employed bee is unable to improve its 
solution in a given number $N_{\max }$ of time steps, a new solution is randomly assigned. The definition of this iteration control parameter $N_{\max }$ is very important in the optimization process.

The general algorithm of ABC method is given by [25]:

1. Initialize

2. Repeat

1. Execute employed bees working step

2. Execute onlookers working step

3. Execute scouts working step

4. Save best solution achieved so far as approximation for global optimum

3. Until maximum number of iterations is reached

In practical, four steps are required in order to apply $\mathrm{ABC}$ method optimization. The inputs are the swarm size $m$, the number

$D$ of parameters to optimize over, the total iteration number $N_{\text {total }}$ and the number of iterations $N_{\text {max }}$ for every employed bee it abandons its actual food source if its solution hasn't improved.

Step 1: An initial solution is obtained randomly for the employed bees by:

$$
X_{i, j}=X_{\min , j}+\epsilon \cdot\left(X_{\max , j}-X_{\min , j}\right)
$$

where $i \in\{1,2, \ldots, m / 2\}, j \in\{1,2, \ldots, D\}, X_{\min , j}$ and $X_{\max , j}$ are the lower and upper limit values for the parameter indexed by $j$ and $\epsilon$ is a random number uniformly distributed in the interval $[0,1]$.

For each solution, a fitness value is calculated according to:

$$
\text { fit }_{i}= \begin{cases}\frac{1}{1+f\left(X_{i}\right)}, & f\left(X_{i}\right) \geq 0 \\ 1+\left|f\left(X_{i}\right)\right|, & f\left(X_{i}\right)<0\end{cases}
$$

where $f$ is the function to optimize.

Step 2.1: For each employed bee, an additional solution is calculated: 


$$
V_{i, j}=X_{i, j}+\varphi_{i, j}\left(X_{i, j}-X_{k, j}\right)
$$

Where the index $j$ is chosen randomly from $\{1,2, \ldots, D\}$, the index $k$ is chosen randomly from $\{1,2, \ldots, m / 2\}$ and $\varphi_{i, j}$ is a random number uniformly distributed in the interval $[-1,1]$. The best solution is selected between $V_{i, j}$ and $X_{i, j}$ based on their fitness values.

Step 2.2: For each onlooker bee a new solution $X_{i}$ from the employed bees is selected with probability:

$$
P_{i}=\frac{f i t_{i}}{\sum_{n=1}^{m / 2} f i t_{n}}
$$

Again, a neighbor solution $V_{i, j}$ is build according to equation (13). In the same way as for the employed bees, the best solution is selected and saved.

Step 2.3: If a solution of an employed bee is not improved until the limit of iterations is reached, the corresponding solution is then replaced by a new one obtained via equation (11).

Step 2.4: Save best solution found so far for output.

The process is completed when the total number of iterations $N_{\text {total }}$ is reached hence the optimal solution can be recovered.

\section{ARTIFICIAL BEE COLONY ALGORITHM FOR MAGNETIC HYSTERESIS PARAMETER IDENTIFICATION}

The aim is to find the optimal parameters for accurate hysteresis description. The ABC method is tested on two different hysteresis models; simpler Fröhlich model and more complex Jiles-Atherton model.

The objective function is defined for one loop identification as:

$$
f=\frac{1}{N} \sqrt{\sum_{i=1}^{N}\left(\frac{B_{i, \text { meas }}-B_{i, s i m}}{\max \left(B_{\text {meas }}\right)}\right)^{2}}
$$

Where $N$ is the number of measured points of the hysteresis loop, $B_{i, m e a s}$ denotes the $i^{\text {th }}$ measured value of the magnetic flux density and $B_{i, s i m}$ corresponds to the $i^{t h}$ value of magnetic flux density predicted by the magnetic hysteresis model. For several loops identification the area per cycle between measurements and simulation is also taken into account [16]. In this case the total objective function is given by: 


$$
f=\sum_{k=1}^{s} f_{k}
$$

Where $f_{k}$ is the objective function corresponding to each hysteresis loop and $\mathrm{s}$ is the number of used loops.

\section{Results}

For this first step in ABC method investigation, we will focus on Fröhlich model. For this model the solution can be computed analytically too. Finally, Jiles-Atherton with 5 parameters will be tested. The comparison will be made on numerical signal and then measured ones.

\section{A. Fröhlich Model}

For this calculation the swarm size: $m=300$ and the maximum number of iterations is set at 40 . The analytical solution of both parameters: $\alpha$ and $\beta$ are obtained using Eq. 9 and Eq.10. From measured signal $B_{s}=1.65$ Tesla, $H_{s}=3414 \mathrm{~A} / \mathrm{m}, B_{r}=0.93$ tesla and $H_{c}=417.8 \mathrm{~A} / \mathrm{m}$. This solution is also used to define the interval variation of the both parameters in the initialization state of the $\mathrm{ABC}$ algorithms.

Fig.2 denotes the comparison between experimental hysteresis loop and modeled curves obtained respectively via $\mathrm{ABC}$ method and the analytical calculation. It is noticed that $\mathrm{ABC}$ method, shows lower error with $1.75 \%$.

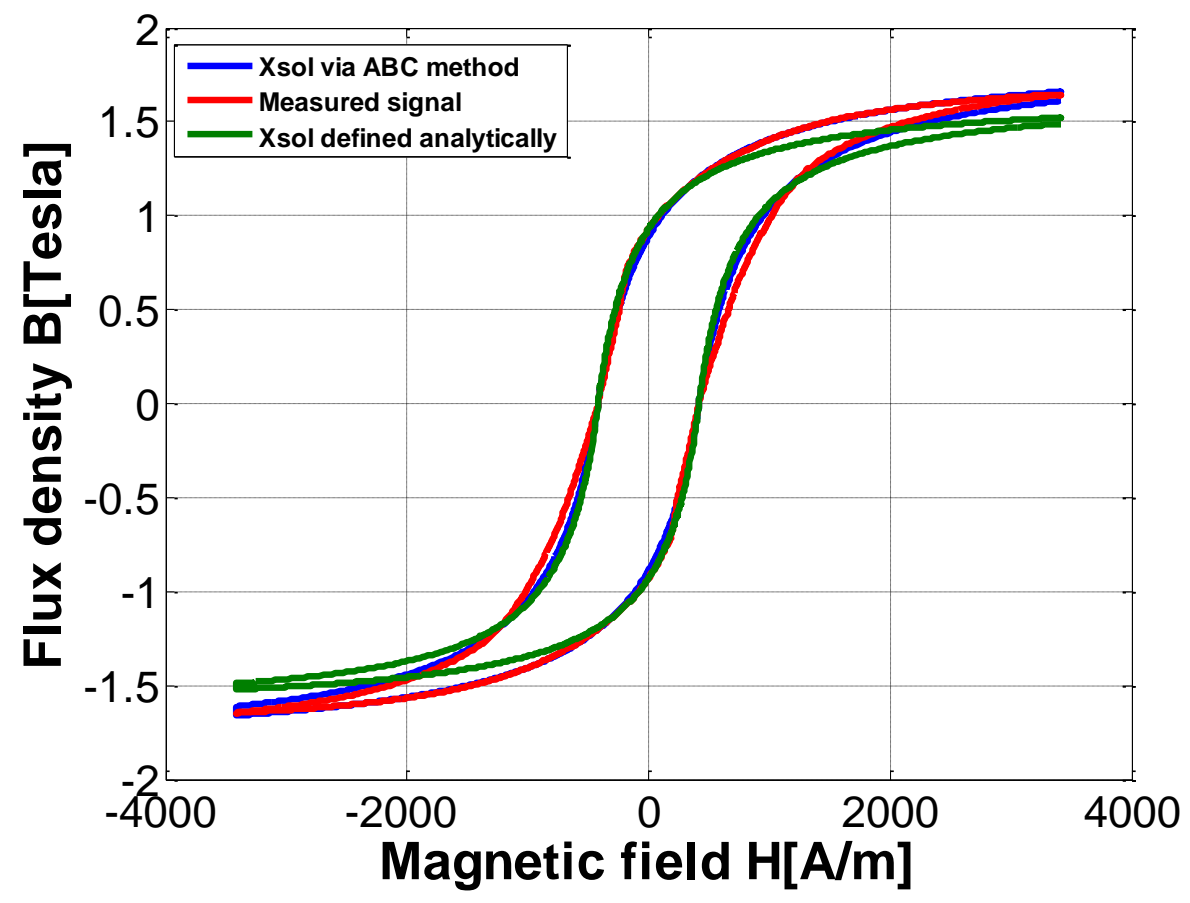

Fig. 2.Measured and simulated hysteresis curves generated with Fröhlich model 
The optimized parameters are detailed in TABLE.I.

TABLE I. Frôhlich parameters obtained by ABC method

using experimental hysteresis loop

\begin{tabular}{cccc}
\hline $\begin{array}{c}\text { Fröhlich } \\
\text { parameters }\end{array}$ & $\begin{array}{c}\text { Variable } \\
\text { range }\end{array}$ & $\begin{array}{c}\text { Analytical } \\
\text { method }\end{array}$ & $\begin{array}{c}\text { ABC } \\
\text { method }\end{array}$ \\
\hline$\alpha$ & $0-400$ & 195.55 & 244.42 \\
$\beta$ & $0-1$ & 0.60 & 0.53 \\
\hline \hline
\end{tabular}

The Fig. 3 shows the error evolution $\mathrm{f}$ with the iteration number. The algorithms converged quickly and the error is decreasing in the first iteration steps.

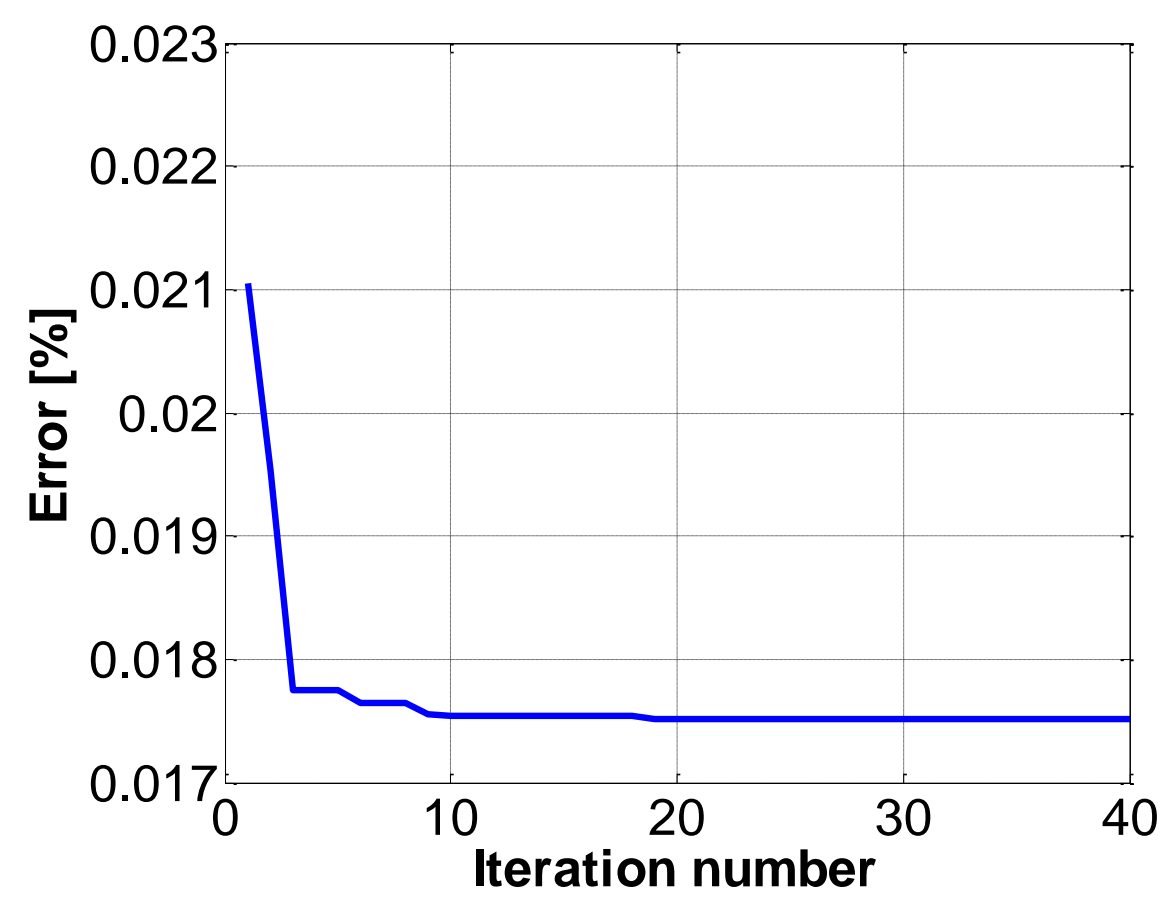

Fig. 3. Error evolution with iteration number for Fröhlich parameters identification

A good estimation of Fröhlich parameters allows using it in applications which require a very expensive computing time such as finite element method integration. 


\section{B. Jiles- Atherton Model}

At the beginning, the optimization is carried out on the generated hysteresis loop via parameters from literature [8] (Ms, $a, \alpha$, $k, c)$. The swarm size $m=300$ and the number of iteration is set at 200. Fig.4 shows the simulated hysteresis curves built via values of reference [8] and via optimized parameters (ABC method). The results are quite good and offer a total mean error of $1.3 \%$.

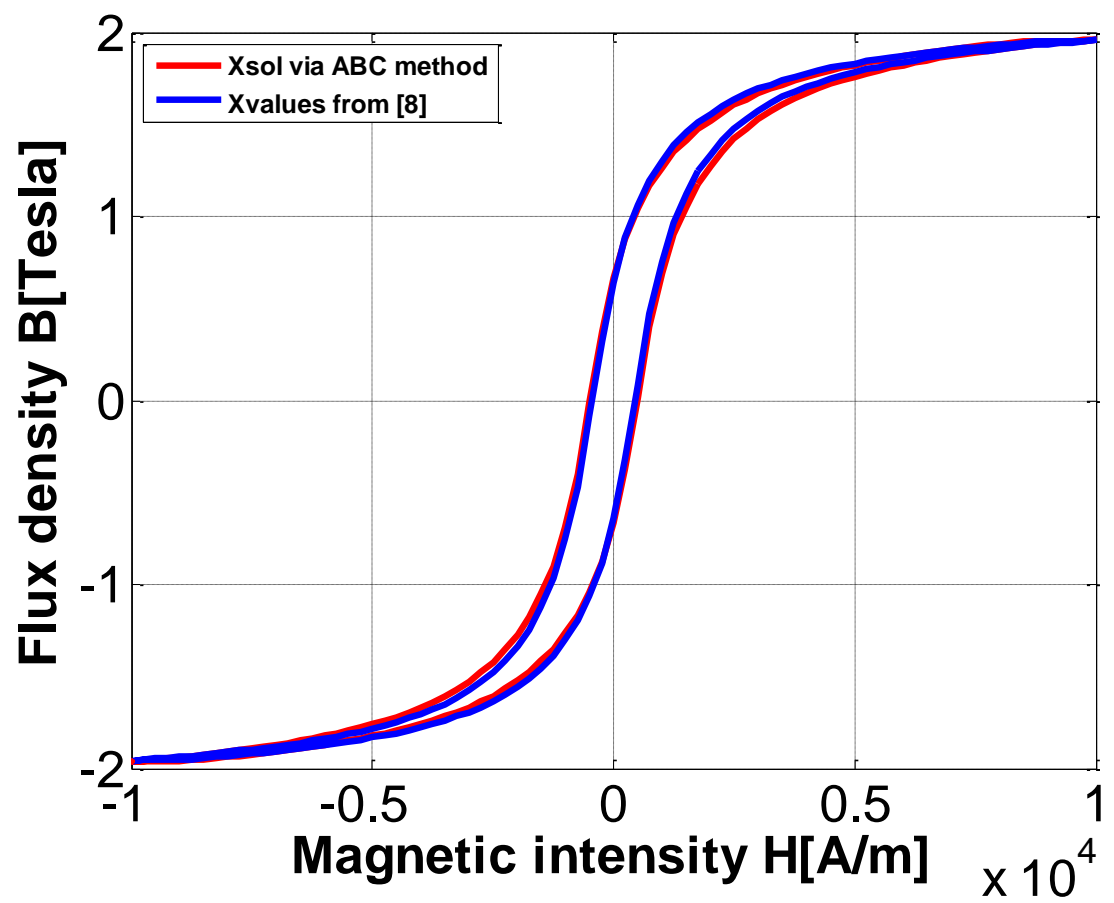

Fig. 4. Calculated and theoretical hysteresis curves generated by the Jiles- Atherton model

The values of calculated parameters are detailed in Table II.

TABLE II. Jiles Atherton parameters obtained by ABC method

\begin{tabular}{cccc}
\hline \hline JA parameters & $\begin{array}{c}\text { Variable } \\
\text { range }\end{array}$ & Values of literature [8] & $\begin{array}{c}\text { ABC } \\
\text { method }\end{array}$ \\
\hline$M s$ & $1.6 \times 10^{6}-1.8 \times 10^{6}$ & $1.7 \times 10^{6}$ & $1.75 \times 10^{6}$ \\
\hline$a$ & $800-1500$ & 1000 & 1337 \\
\hline$\alpha$ & $1 \times 10^{-3}-1.5 \times 10^{-3}$ & $1 \times 10^{-3}$ & $1.5 \times 10^{-3}$ \\
\hline$k$ & $400-800$ & 500 & 490 \\
\hline$c$ & $0.05-0.5$ & 0.1 & 0.08 \\
\hline \hline
\end{tabular}


validation of the proposed method with experimental data is illustrated in Fig.5. The measured hysteresis loop is the same as that presented in Fröhlich model. The number of bees is taken 300 and the iteration number is 200. The range of parameters is chosen after several trials. The number of bees plays a very important role in the optimization process.

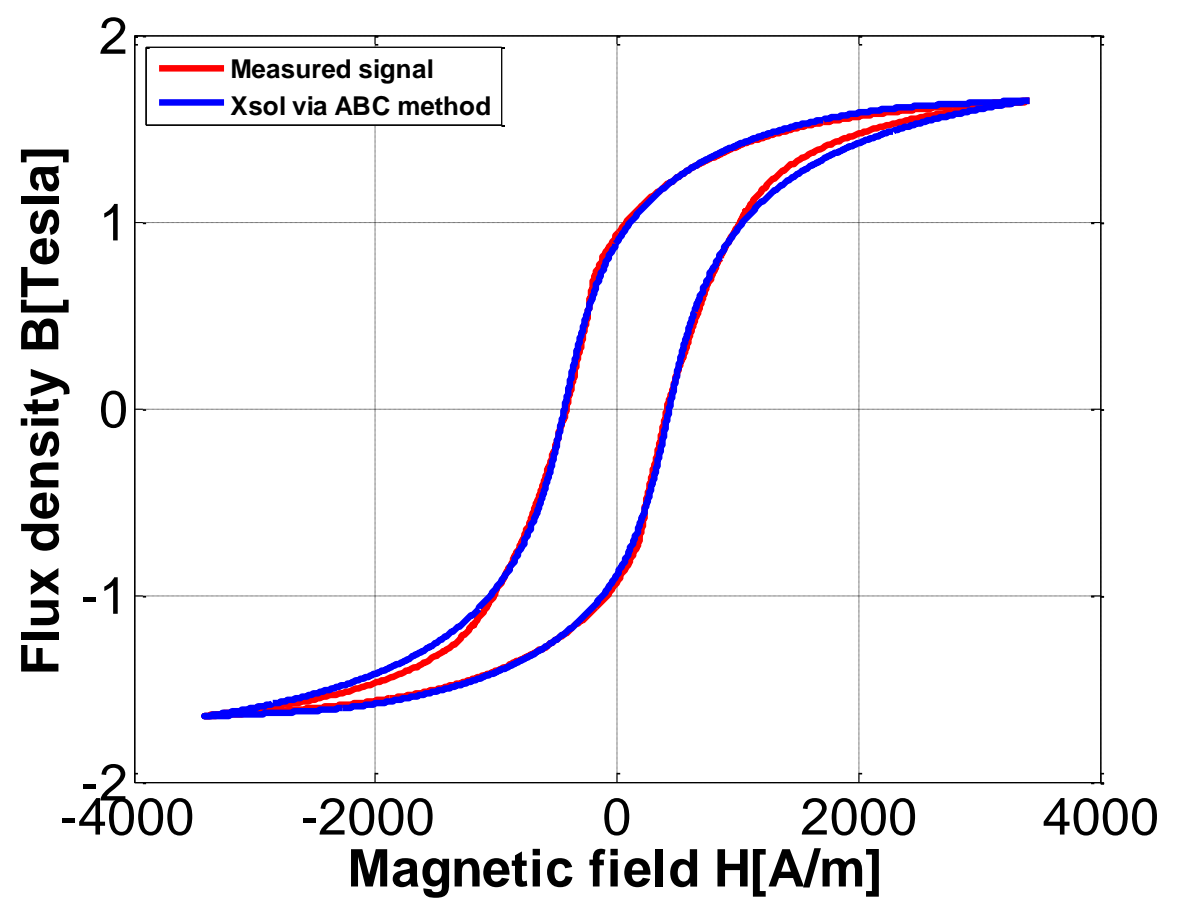

Fig. 5. Measured and hysteresis curves generated by the Jiles- Atherton model for the first experimental loop

The obtained parameters are presented in Table III.

TABLE III. Jiles Atherton parameters obtained by ABC method using first experimental loop

\begin{tabular}{ccc}
\hline \hline JA parameters & $\begin{array}{c}\text { Variable } \\
\text { range }\end{array}$ & $\begin{array}{c}\text { ABC } \\
\text { method }\end{array}$ \\
\hline$M s$ & $1.6 \times 10^{6}-1.7 \times 10^{6}$ & $1.61 \times 10^{6}$ \\
\hline$a$ & $200-1500$ & 882.55 \\
\hline$\alpha$ & $1 \times 10^{-3}-8 \times 10^{-3}$ & $1.34 \times 10^{-3}$ \\
\hline$c$ & $200-800$ & 742.64 \\
\hline \hline
\end{tabular}


A good representation of hysteresis loop is run via $\mathrm{ABC}$ optimization method. The error evolution is presented in Fig.6, the convergence is slower in this case because of the large number of parameters to identify.

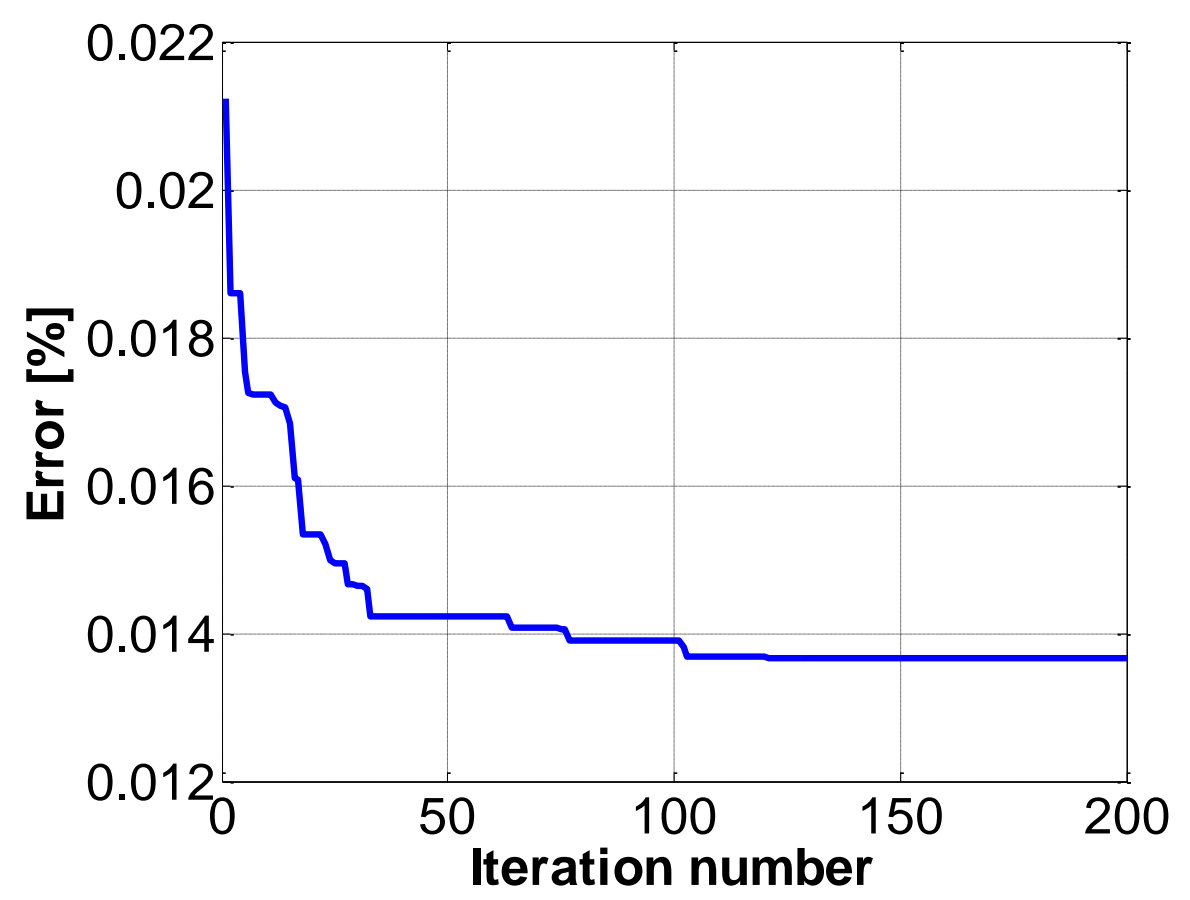

Fig. 6. Error evolution with iteration number for Jiles-Atherton parameter identification for the first experimental loop

To see the efficiency of the ABC method, it is applied for the identification of six loops with different maximum flux densities. Fig. 7 shows comparison between three measured loops and modeled ones. The corresponding parameters are given in TableIV. 


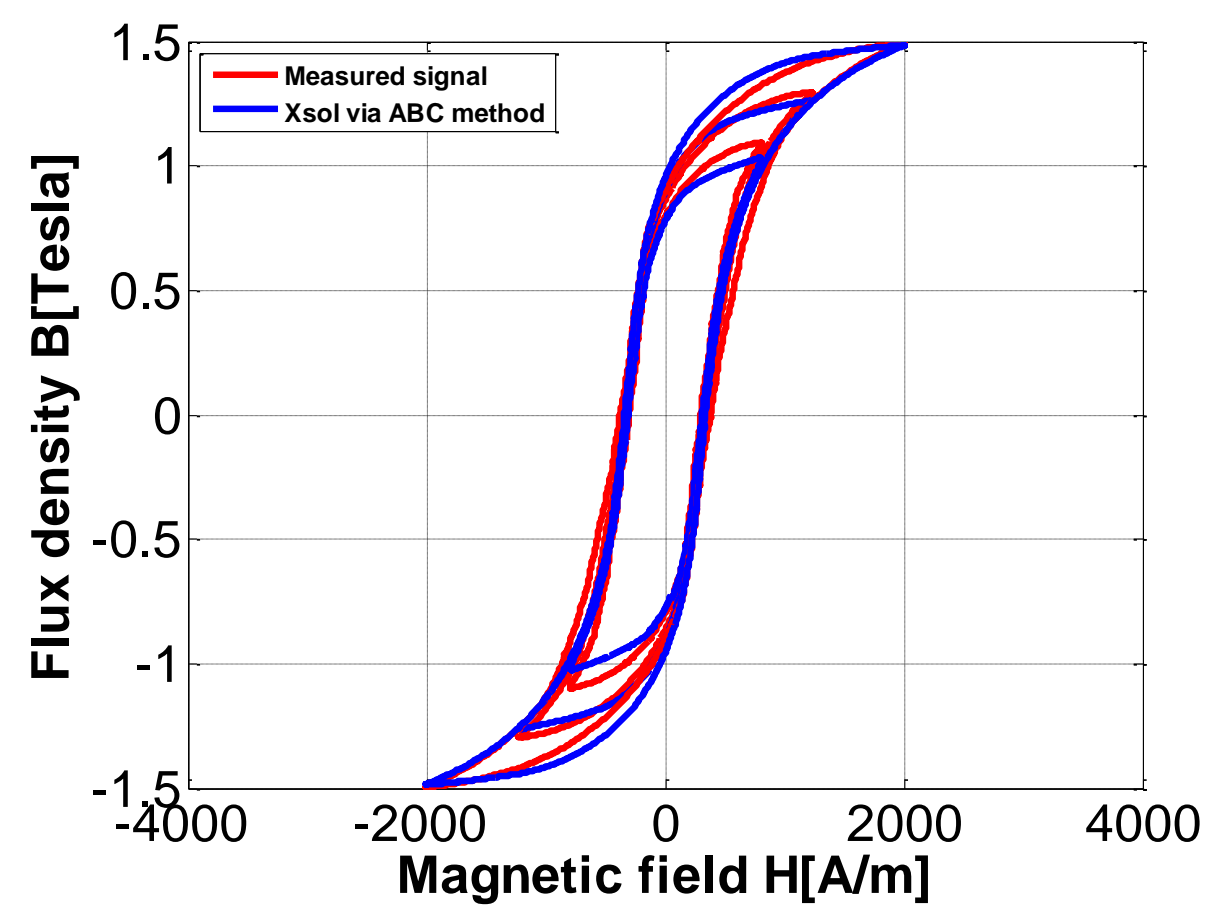

Fig. 7. Measured and hysteresis curves generated by the Jiles- Atherton model for different maximum flux densities for the first experimental loop

The application of the ABC method for the identification of several measured loops gives correct results, accuracy can be improved by adding the number of measured loops.

TABLE IV. Jiles Atherton parameters obtained by ABC method using several measured loops with different maximum flux densities for first experimental loops

\begin{tabular}{ccc}
\hline \hline JA parameters & $\begin{array}{c}\text { Variable } \\
\text { range }\end{array}$ & $\begin{array}{c}\text { ABC } \\
\text { method }\end{array}$ \\
\hline$M s$ & $1.5 \times 10^{6}-1.7 \times 10^{6}$ & $1.54 \times 10^{6}$ \\
\hline$a$ & $200-1500$ & 658.55 \\
\hline$\alpha$ & $1 \times 10^{-3}-8 \times 10^{-3}$ & $1.1 \times 10^{-3}$ \\
\hline$k$ & $500-800$ & 613.152 \\
\hline$c$ & $0.1-0.9$ & 0.35 \\
\hline \hline
\end{tabular}


In Fig.8 the procedure is also validated by comparing experimental and simulated hysteresis loop for Fe-Si material.

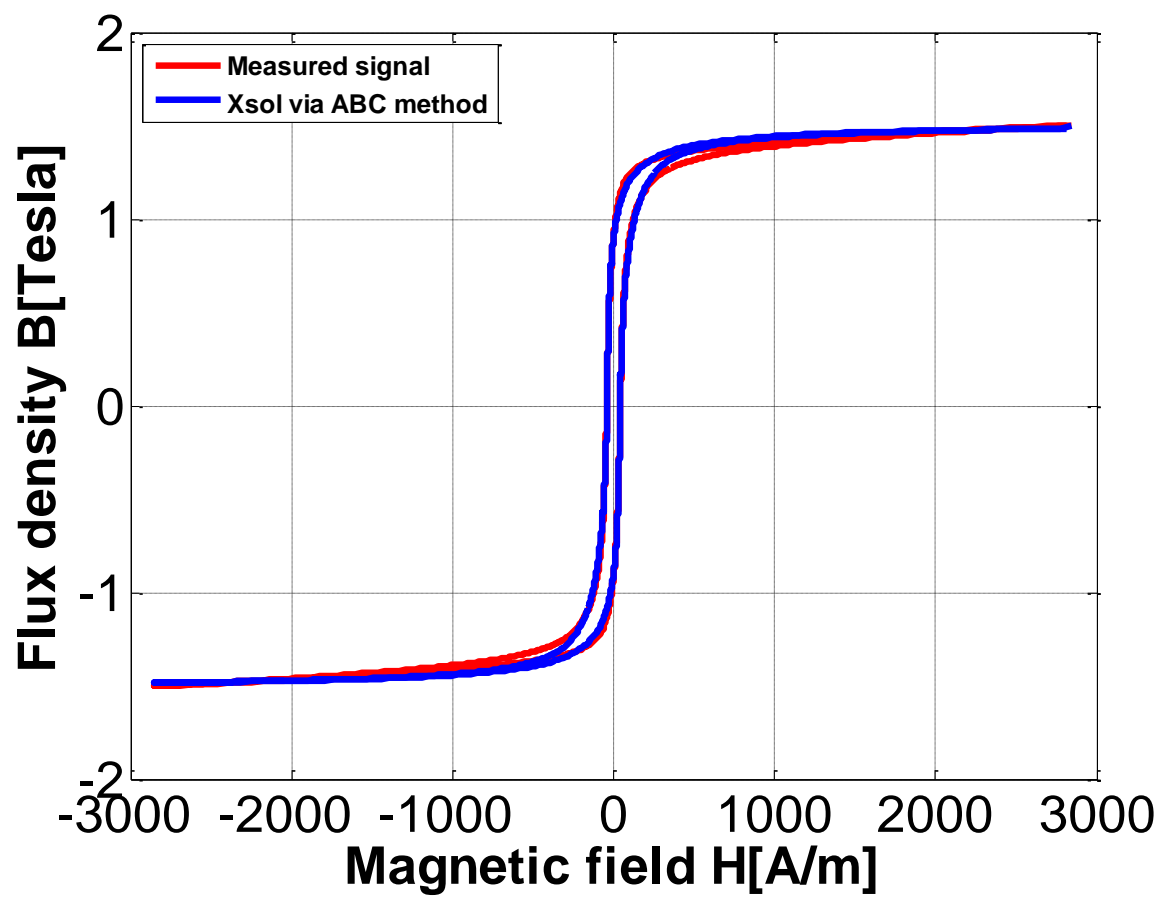

Fig. 8. Measured and hysteresis curves generated by the Jiles- Atherton model for Fe-Si material

The obtained parameters are presented in Table V.

TABLE V. Jiles Atherton parameters obtained by ABC method using Fe-Si experimental loop

\begin{tabular}{ccc}
\hline \hline JA parameters & $\begin{array}{c}\text { Variable } \\
\text { range }\end{array}$ & $\begin{array}{c}\text { ABC } \\
\text { method }\end{array}$ \\
\hline$M s$ & $1 \times 10^{6}-1.7 \times 10^{6}$ & $1.2 \times 10^{6}$ \\
\hline$a$ & $30-200$ & 49.7 \\
\hline$\alpha$ & $1 \times 10^{-5}-1 \times 10^{-3}$ & $1.12 \times 10^{-4}$ \\
\hline$k$ & $30-200$ & 71 \\
\hline$c$ & $0.01-0.9$ & 0.24 \\
\hline \hline
\end{tabular}

To obtain a good approximation of hysteresis for $\mathrm{Fe}-\mathrm{Si}$, the program is executed for a number of iterations equal to 200 and $m=400$.The error evolution is presented in Fig.9. 


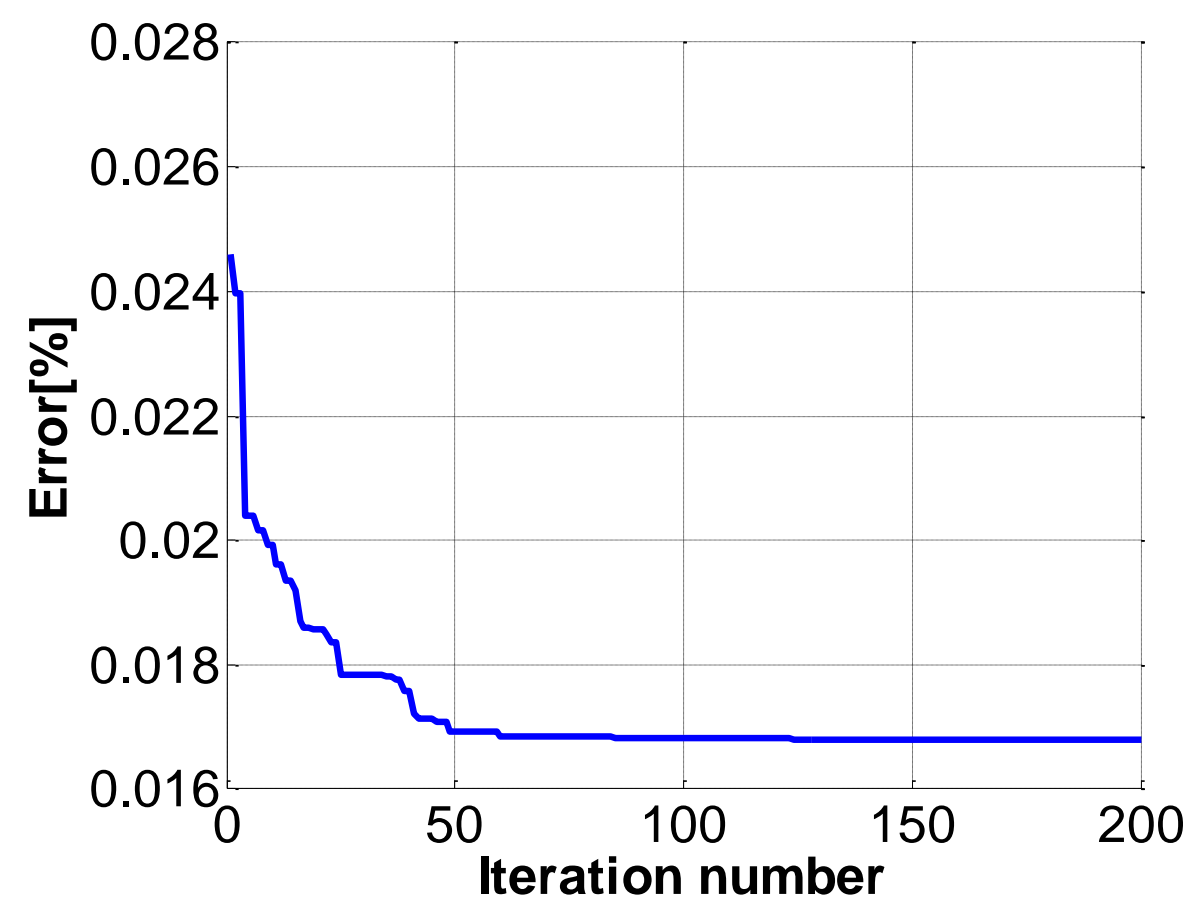

Fig. 9. Error evolution with iteration number for Jiles-Atherton parameter identification for Fe-Si material

In the same way Fig.10 gives the results of the identification done on several hysteresis curves at different maximum flux densities of Fe-Si material. The obtained parameters shown in Table VI allow a very good representation of hysteresis loops.

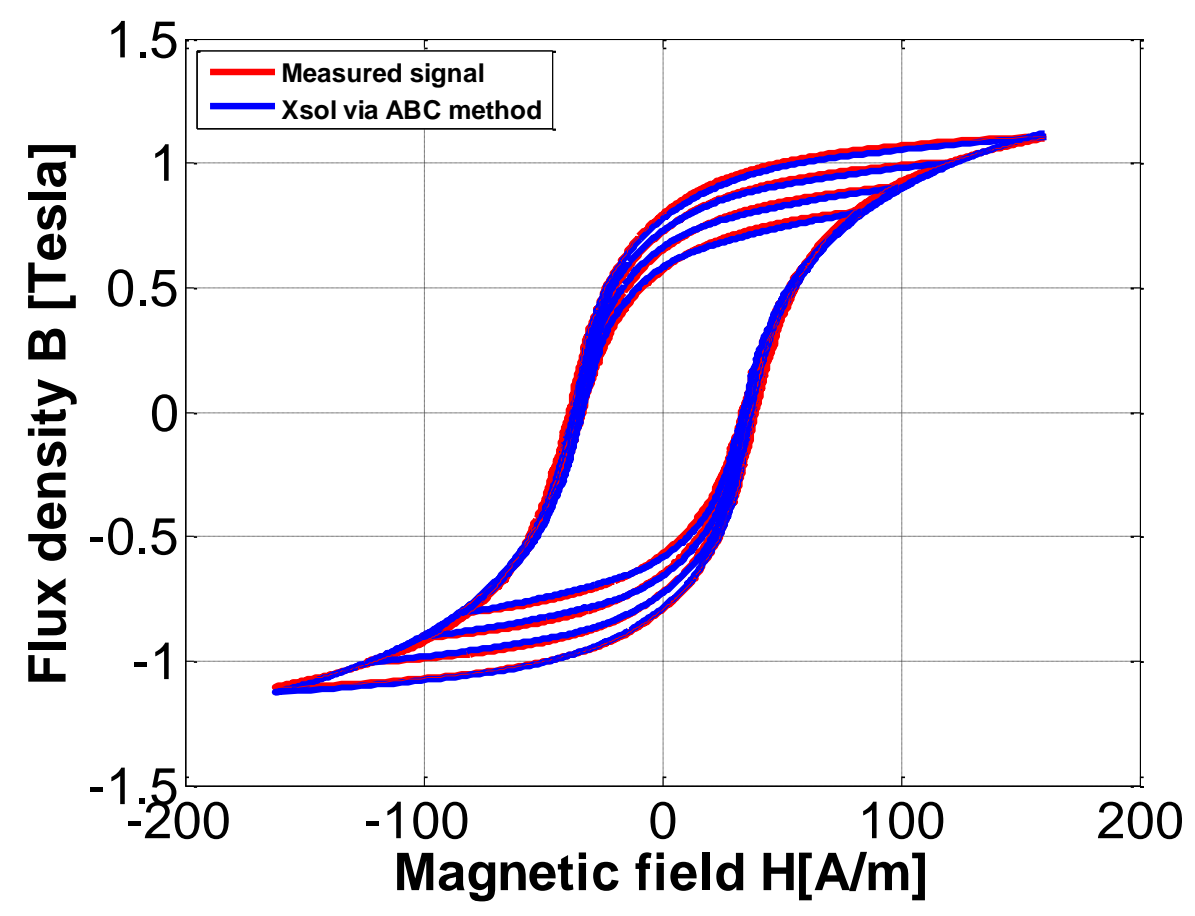

Fig. 10. Measured and hysteresis curves generated by Jiles- Atherton model for different maximum flux densities for Fe-Si material 
TABLE VI. Jiles Atherton parameters obtained by ABC method

using several measured loops with different maximum flux densities for Fe-Si experimental loops

\begin{tabular}{ccc}
\hline \hline JA parameters & $\begin{array}{c}\text { Variable } \\
\text { range }\end{array}$ & $\begin{array}{c}\text { ABC } \\
\text { method }\end{array}$ \\
\hline$M s$ & $1 \times 10^{6}-1.5 \times 10^{6}$ & $1.33 \times 10^{6}$ \\
\hline$a$ & $60-150$ & 85.7 \\
\hline$\alpha$ & $1 \times 10^{-5}-1 \times 10^{-3}$ & $1.8 \times 10^{-4}$ \\
\hline$c$ & $60-150$ & 81.75 \\
\hline \hline
\end{tabular}

\section{Conclusion}

For the first time the ABC, BEE principal algorithms is applied on hysteresis identification problem. The advantage of this algorithm is that it requires only few parameters. The robustness of this method is assessed on comparison between measured and calculated signal on Frölich and JA model, the first with 2 independent parameters and the second with 5 dependent parameters, the $\mathrm{ABC}$ method can accurately describe measured hysteresis loops. The algorithm converges in a short time and offers high accurate results. The rate of convergence depends on the number of parameters to be identified. For both models the program gives good results from a number of bees equal to 300. For both tested materials, the characteristic points and the surface of the loops which represent the hysteresis losses agree very well with those of measured ones. This method shows the ability to give good results for the identification of several loops with different maximum flux densities too.

As a perspective, complex hystesresis loops will be tested such as: minor asymmetric curves, reversal loops...

\section{REFERENCES}

[1] Lord Rayleigh, " The behaviour of iron and steel under the operation of feable magnetic force," Phil. Mag., vol. 23, pp. 225-245, 1887.

[2] R. I Potter, "Self-Consistently computed magnetization patterns in thin magnetic recording media," Trans. Mag., vol. Mag-7, pp. 873-880, 1971.

[3] O. Fröhlich, "Investigation of dynamo electric machines and electric power transmissionand theoretical conclusions there from," Electrotech Z.2,134-141., vol. 2, pp. 134-141, 1881.

[4] A. Akbaba, "A modified Fröhlich's type equation for accurate modeling of magnetizing characteristics of magnetic cores," Electrical machines and power systems, vol. 19, pp. 303-311, 1991.

[5] K. Hergly, H.Marouani and M. Zidi "Identification models : A review," design and modeling of Mechanical systems, vol. III, pp. 189-198, 2007. 
[6] F. Preisach, "Über die magnetische Nachwirkung," Z. Phys., vol. 94, pp. 277, 1935.

[7] D.C Jiles and D. L. Atherton, "Theory of ferromagnetic hysteresis ," Journal of Magnetism and Magnetic Materials, Volume 61, Issue 1-2, pp. 48-60, September, 1986

[8] D. C. Jiles, J. B. Thoelke, and M. K. Devine "Numerical Determination of Hysteresis Parameters for the Modeling of Magnetic Properties Using the Theory of Ferromagnetic Hysteresis," IEEE Trans. on Magnetics, vol. 28, pp. 27-35, January 1992.

[9] D. Lederer, H. Igarashi, A. Kost, and T. Honma. "On the Parameter Identification and Application of the Jiles-Atherton Hysteresis Model for Numerical Modelling of Measured Characteristics”. IEEE Transs on Magnetics, vol 35,pp 12111214, May 1999.

[10] E.D.M. Hernandez, C. S. Muranka, J. R. Cardozo. "Identification of the Jiles-Atherton parameters using random and deterministic searches".Physica B, vol 275,pp 212-215, Janary, 2000.

[11] P. R. Wilson, J.N. Ross and A.D.Brown "Optimizing the Jiles-atherton Model of Hysteresis by a generic Algorithm". IEEE Trans. on Magnetics, vol. 37, 989-993, March, 2001.

[12] A. Salvini, and F. R. Fulginei "Genetic algorithms and neural networks generalizing the Jiles-Atherton model of static hysteresis for dynamic loops," IEEE Trans. on Magnetics, vol. 38, pp. 873-876, Mars, 2002.

[13] J. V. Leite, S. Avila, N. J. Batistela, W. P. Carpes, Jr. N. Sadowski, P. Kuo-Peng and J. P. Bastos "Real Coded Genetic Algorithm for Jiles-Atherton Model Parameters Identification ," IEEE Trans. on Magnetics, vol. 40, pp. 888-891, Mars, 2004.

[14] F.R. Fulginei and A. Salvini "Softcomputing for the identification of the Jiles-Atherton model parameters ," IEEE Trans. on Magnetics, vol. 41, pp. 1100-1108, Mars, 2005.

[15] J.Kennedy and R.Eberhart, "Particle swarm optimization"in Proc, IEEE. INt. Conf. Neural Network, pp.1942-1948, 1995.

[16] R.Marion, R.Scorretti, N.Siauve, M.A. Raulet and L. Krahenbuhl, "Identification of Jiles Atherton model parameters using particle swarm optimization”. IEEE Trans. on Magnetics, vol. 44, pp 894-897, June, 2008.

[17] L.S. Coelho, F.A. Guerra, and J. V. Leite, "Multiobjective axponential particle swarm optimization approach applied to hysteresis parameters estimation”. IEEE Trans. on Magnetics, vol. 48, pp 283-286, February, 2012.

[18] D. Karaboga. “An Idea Based on Honey Bee Swarm for Numerical Optimization”. Technical Report-TR06, Depar tment of Computer Engineering, Engineering Faculty, Erciyes Univer sity . Press, Erciyes, 2005.

[19] D. Karaboga and B. Basturk, "On performance of artificial Bee Colony (ABC) algorithm”, Applied Soft Computing, vol. 8, no. 1, pp. 687-697,2008.

[20] D. Karaboga and B. Akay, "A comparitive study of Artificial Bee Colony Algorithm", Applied Mathematics and Computation, vol. 214, no. 1, pp. 108-132, 2009.

[21] B. Akay and D. Karaboga, “ A modified Artificial Bee Colony algorithm for real parameter optimization”, Information sciences,vol.192,no. 1, pp. 120-142, 2012

[22] D. Karaboga and B. Gorkemli, "A quick Artificial Bee Colony (qABC) algorithm and its performance on optimization problems", Applied Soft Computing, vol. 23, pp. 227-238,2014.

[23] M.S. Kiran and O.Findik," A directed Artificial Bee Colony algorithm”, Applied Soft Computing, vol. 26, no. C, pp. 454-462,2015.

[24] S. K. Nseef, S. Abdullah, A. Turky and G. Kendall,"An adaptative mutipopulation Artificial Bee Colony algorithm for dinamic optimization problems" Knowledge-based systems, vol. 104, pp. 14-23,2016.

[25] D.Karaboga, “Artificial bee colony algorithm”. Scholarpedia, 5(3), 6915. ttps://doi.org/10.4249/scholarpedia.6915,2010. 